Check for updates

New York

Cite this as: BMJ 2021;373:n897 http://dx.doi.org/10.1136/bmj.n897 Published: 6 April 2021

\section{Covid-19: All Johnson and Johnson vaccine in use is safe, says US regulator}

\author{
Janice Hopkins Tanne
}

The acting head of the US Centers for Medicare and Medicaid Services gave reassurances on 5 April that the Johnson \& Johnson vaccine was safe, after a mix-up at a production plant in Maryland ruined 15 million potential doses of the vaccine. ${ }^{1}$

Andy Slavitt said at a press briefing, “All of the Johnson \& Johnson vaccine that's available in the US has been authorised by the FDA [Food and Drug Administration]. None of it came out of this plant ... No vaccine will leave any factory unless authorised by the FDA ...

“The Johnson \& Johnson vaccine [will be] the only vaccine made in this plant, to eliminate any potential for cross contamination."

The Emergent BioSolutions pharmaceutical plant in Baltimore, Maryland, was a partner with Johnson \& Johnson in producing a single dose vaccine approved by the FDA for use in the US, as well as with AstraZeneca, whose vaccine has not yet been authorised in the US. Workers at the Emergent plant accidentally mixed ingredients for the two vaccines several weeks ago. The problem was detected in quality control checks before the manufacture of any vaccines was completed. ${ }^{23}$

Johnson \& Johnson took control of production of its vaccine at the plant and said that it was "providing additional experts in manufacturing, technical operations, and quality to be on site at Emergent to supervise, direct, and support all manufacturing of the Johnson \& Johnson covid-19 vaccine. In coordination with the US Department of Health and Human Services, these steps will enable us to safely deliver an additional 24 million single shot vaccine doses through April."

Anthony Fauci, director of the National Institute of Allergy and Infectious Diseases, said at the briefing, "J\&J has assured us that they will actually have the 100 million doses by the end of May as they promised."

On 3 April more than four million doses of vaccine were administered in a single day, and about $25 \%$ of the US adult population have been fully vaccinated. ${ }^{1}$ More than 555000 Americans have died with covid-19, and new cases average more than 64000 a day-an increase of $18 \%$ from two weeks ago, the New York Times reported. ${ }^{4}$

1 US White House. Press briefing by White House Covid-19 response team and public health officials. 5 Apr 2021. https://www.whitehouse.gov/briefing-room/pressbriefings/2021/04/05/press-briefing-by-white-house-covid-19-response-team-and-public-health-officials-24/.

2 LaFraniere S, Weiland N. Factory mix-up ruins 15 million doses of vaccine from Johnson \& Johnson. New York Times 2021 Mar 31. https://www.nytimes.com/2021/03/31/us/politics/johnson-johnson-coronavirus-vaccine.html.

3 Johnson \&Johnson. Statement on US Covid-19 vaccine manufacturing. 31 Mar 2021. https://www.jnj.com/johnson-johnson-statement-on-u-s-covid-19-vaccinemanufacturing.

4 Coronavirus in the US: latest map and case count. New York Times 2021 Apr 5. https://www.nytimes.com/interactive/2020/us/coronavirus-us-cases.html.

This article is made freely available for use in accordance with BMJ's website terms and conditions for the duration of the covid-19 pandemic or until otherwise determined by BMJ. You may use, download and print the article for any lawful, non-commercial purpose (including text and data mining) provided that all copyright notices and trade marks are retained. 